\title{
The Wind Farm Aggregation Impact on Power Quality
}

Conference Paper NREL/CP-500-39870

November 2006

\section{Preprint}

\section{J.T. Bialasiewicz}

University of Colorado at Denver

E. Muljadi

National Renewable Energy Laboratory

To be presented at the 32nd Annual Conference of the IEEE Industrial Electronics Society (IECON '06)

Paris, France

November 7-10, 2006
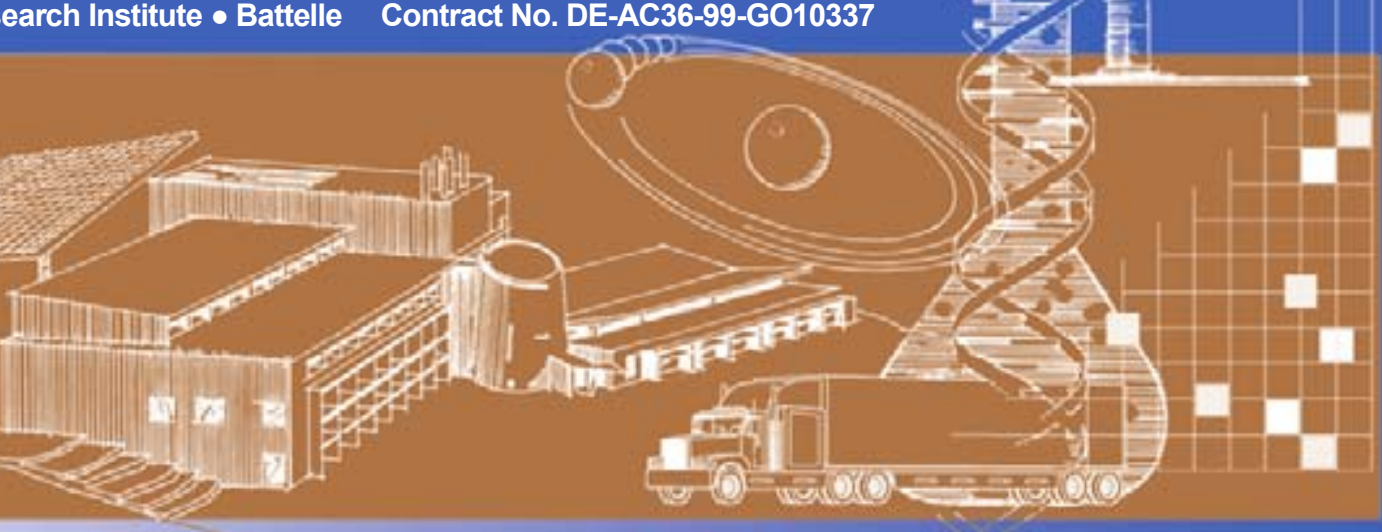


\section{NOTICE}

The submitted manuscript has been offered by an employee of the Midwest Research Institute (MRI), a contractor of the US Government under Contract No. DE-AC36-99G010337. Accordingly, the US Government and MRI retain a nonexclusive royalty-free license to publish or reproduce the published form of this contribution, or allow others to do so, for US Government purposes.

This report was prepared as an account of work sponsored by an agency of the United States government. Neither the United States government nor any agency thereof, nor any of their employees, makes any warranty, express or implied, or assumes any legal liability or responsibility for the accuracy, completeness, or usefulness of any information, apparatus, product, or process disclosed, or represents that its use would not infringe privately owned rights. Reference herein to any specific commercial product, process, or service by trade name, trademark, manufacturer, or otherwise does not necessarily constitute or imply its endorsement, recommendation, or favoring by the United States government or any agency thereof. The views and opinions of authors expressed herein do not necessarily state or reflect those of the United States government or any agency thereof.

Available electronically at http://www.osti.gov/bridge

Available for a processing fee to U.S. Department of Energy and its contractors, in paper, from:

U.S. Department of Energy

Office of Scientific and Technical Information

P.O. Box 62

Oak Ridge, TN 37831-0062

phone: 865.576 .8401

fax: 865.576 .5728

email: mailto:reports@adonis.osti.gov

Available for sale to the public, in paper, from:

U.S. Department of Commerce

National Technical Information Service

5285 Port Royal Road

Springfield, VA 22161

phone: 800.553 .6847

fax: 703.605.6900

email: orders@ntis.fedworld.gov

online ordering: http://www.ntis.gov/ordering.htm 


\section{The Wind Farm Aggregation Impact on Power Quality}

\author{
Jan T. Bialasiewicz \\ Department of Electrical Engineering \\ Univ. of Colorado at Denver and Health Sciences Center \\ CB 110, P.O. Box 173364 \\ Denver, Colorado 80217-3364 \\ jan.bialasiewicz@cudenver.edu
}

\author{
Eduard Muljadi \\ National Wind Technology Center \\ National Renewable Energy Laboratory \\ 1617 Cole Boulevard \\ Golden, Colorado 80401 \\ eduardmuljadi@nrel.gov
}

\begin{abstract}
This paper explores the effects of wind farm power fluctuations on the power network. A dynamic simulation of a wind farm is performed and the spatial distribution of the wind turbines is considered. In a wind farm, many wind turbines feed power into the power grid at the point of common coupling. The power fluctuation from one turbine may cancel that of another, which effectively rectifies the power fluctuation of the overall wind farm. The effect of power fluctuations is quantified by measuring the flicker and the voltage variation for different case studies.

We took a conservative approach to explore a wind farm that consists mainly of stall-controlled wind turbines with fixed frequency induction generators and a specified grid with a known short circuit capacity.
\end{abstract}

\section{INTRODUCTION}

The power fluctuation at each wind turbine is affected by the type of turbine, the control algorithm, the wind speed fluctuation, and the tower shadow effect. The power measurement from a single wind turbine usually shows a large fluctuation of output power. Because many turbines are connected in a wind farm, the power fluctuation from one turbine may cancel that of another, which effectively rectifies the power fluctuation of the overall wind farm.

As wind energy technologies progress, wind turbines become larger. Manufacturers are currently producing multimegawatt wind turbines. Thus, fewer turbines are needed to deliver the same power and the power fluctuation of an individual wind turbine will have a greater impact on the power network. The impact on a weak grid will be even greater.

We used a simulation program to investigate the impact of the turbine distribution on a large wind farm. Many researchers have investigated various aspects of electrical power systems on a wind farm. Wind farms with variable speed [1-2] or fixed speed wind turbines [3-4] were investigated under varying conditions. The voltage fluctuations as a function of $\mathrm{X} / \mathrm{R}$ ratio, the reactive power fluctuations on voltage variation, the harmonics components at the point of common coupling (PCC), and the flicker emission out of a wind farm were presented in reference [5] and reference [6]. The flicker emission from a wind farm is reduced as the grid stiffness ( $\mathrm{Sk} / \mathrm{Sn}$ ratio) increases [7]. Also, the flicker emission is affected dramatically by the turbulence intensity. The flicker emission at $16 \%$ turbulence intensity is twice as high as a turbulence intensity of $8 \%$ [8].

In this paper, we focus on the aggregation impact on the wind farm output at the PCC. We used the same wind turbulence intensity and impedance of the transmission line and measured the real and reactive power fluctuations, the voltage fluctuations, and the flicker emission (using design specification in IEC 61000-4-15[9]) at the PCC of a wind farm. By quantifying the difference in power and voltage fluctuations and flicker level, we were able to treat a wind farm as a single turbine or as multiple groups of turbines.

Ideally, we would like to model every wind turbine on the wind farm. Unfortunately, a large wind farm can have more than 100 turbines on site. Therefore, all the turbines cannot be represented simultaneously, because the computing time will be excessive. This study introduces a properly defined aggregation model that closely represents a real wind farm without simulating each turbine. Section II presents the aggregation model structure and assumptions for a large wind farm; Section III reports the results of the aggregation impact analysis; Section IV provides a comparison of real power, reactive power, and voltage at the PCC for two wind farm models; and Section V summarizes the paper.

\section{AGGREGATION CHARACTERISTICS OF A LARGE WIND FARM}

Each wind turbine is represented by an induction machine and a stall-controlled wind turbine with a rated power of 225 kilowatts $(\mathrm{kW})$. Reactive power compensation in each turbine is provided by a 99 kilovar (kvar) capacitor. The wind turbine is operated at a fixed frequency and its tower shadow is set to reduce the wind speed by $20 \%$ every time a blade passes in front of the tower. The duration of time a blade passes the tower is represented by an arc of $10 \%$ out of 120 degrees for a three-bladed turbine. Three pulsations are created by tower shadow, commonly known as the 3P effect.

We made, the following assumptions for the aggregation model investigated in this research:

- For the total number of 200 wind turbines in the wind farm, we investigate different groupings.

- The wind speed is uniform for each group of wind turbines. The wind speed applied to one group is timeshifted with respect to the other, according to the wind speed and the distance between centers of the wind turbine groups.

- The groups are arranged in sequence: because of the difference in wind speed at each turbine location, all the wind turbines are not started at the same time.

- Our interest is in the long-term simulation.

- All the turbines in the wind farm are exposed to the same time series wind speed with an average speed of 
$18.7 \mathrm{~m} / \mathrm{s}$ and turbulence level of $19.7 \%$. The time series wind speed shifts by 1 minute for each group.

- Power contributions at PCC of each group are chosen randomly.

- The impact of wind turbine distribution is evaluated by comparing the flicker and the voltage fluctuations based on groupings (1 group only and 16 groups).

The electrical output power of the wind turbine is connected to a PCC and then transmitted to an infinite bus. The short circuit capacity of the wind farm is 212 MVA.

In Figure 1, we present an example of wind farm aggregation. The distance between the center of group 1 and group 2 is $\mathrm{d} 2$, and the distance between the center of group 2 and group 3 is $\mathrm{d} 1$. The wind, blowing from the right to the left, will arrive first in group 1, then in group 2, and last in group 3.

The worst case assumption is to consider a wind farm as represented by one group of 200 wind turbines because all the wind turbines in this group will be synchronized and the same wind fluctuations and tower shadow effects of each will affect the output power of the wind farm and the power quality at the PCC. This one-group non-aggregated simulated wind farm is called WF1G. Its power quality is compared to that of the same wind farm that is aggregated into 16 groups of wind turbines (called WF16G). The same wind time series is used in both simulations, but in the latter case we have the
15 -second time shift of the wind speed between groups (to simulate the spatial distribution of turbulence and gust fronts). The electrical output power of the groups is fed into the same PCC on the power grid.

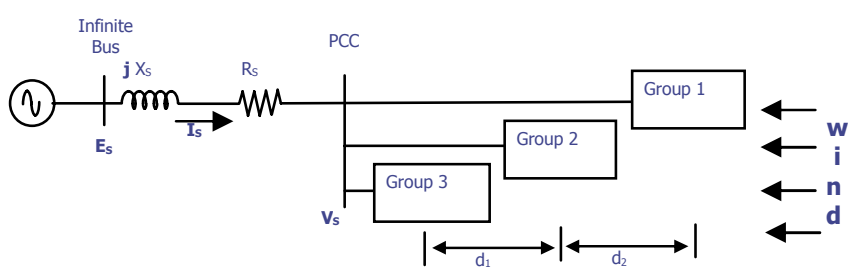

Fig. 1. Three groups of wind turbines are feeding the same transmission line at the PCC.

\section{RESULTS OF AGGREGATION IMPACT ANALYSIS}

Our simulation results show that there is no major difference in the generated real power by each wind turbine in the WF1G model and in the WF16G model. As shown in Figure 2, whether in a WF1G or in a WF16G, a wind turbine driven by the same time series wind speed and affected by its tower shadow will produce a fluctuating power with a maximum average value of about $225 \mathrm{~kW}$.

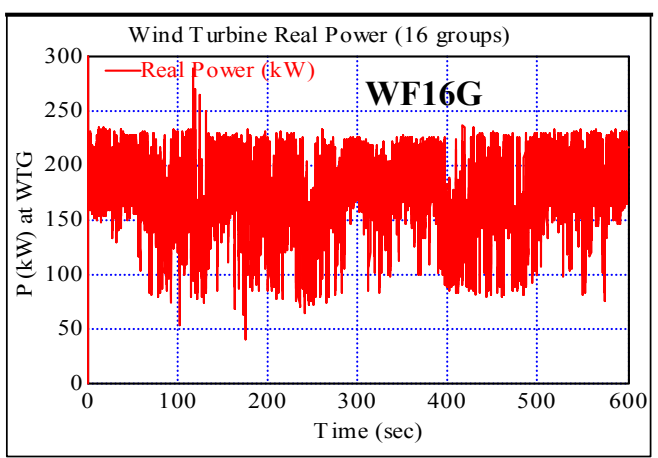

Fig. 2. Real power output of a turbine in a WF1G and in a WF16G.
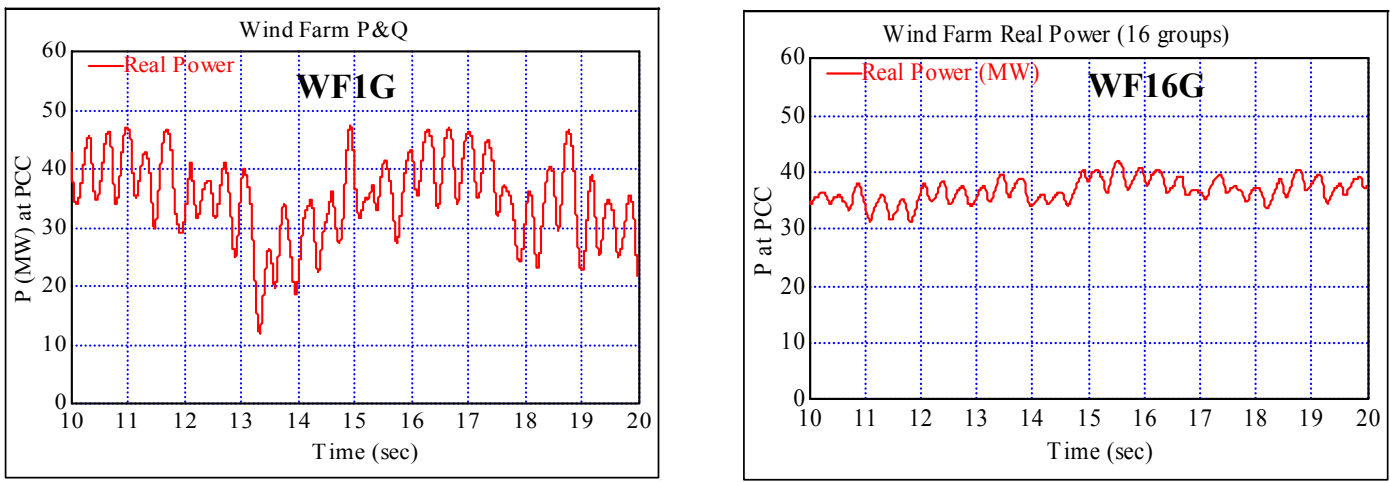

Fig. 3. Real power output of a wind farm in a WF1G and in a WF16G. 

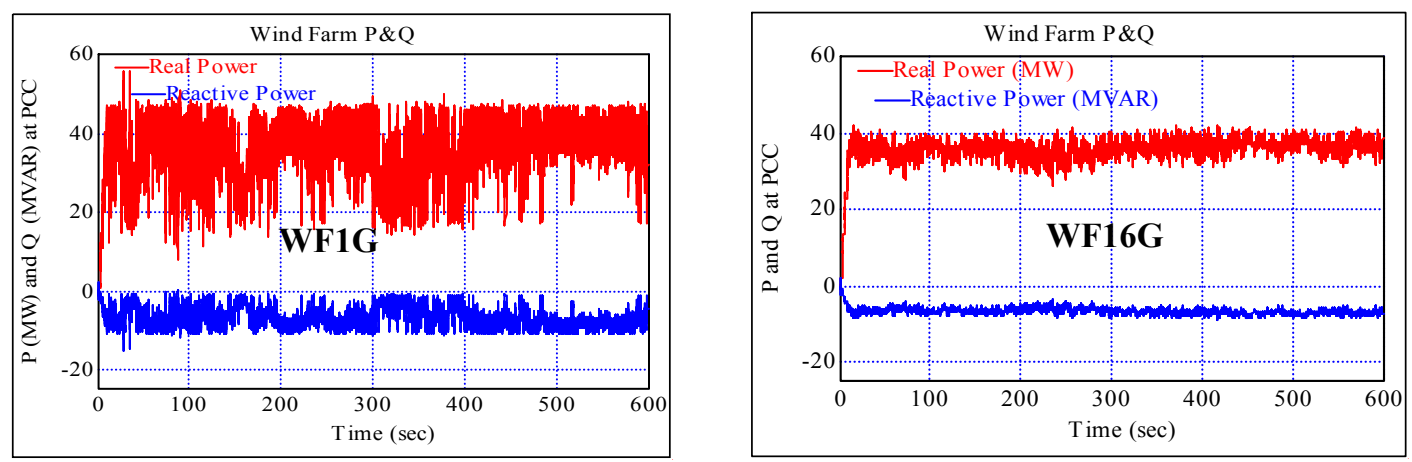

Fig.4. Real power output of a wind farm in a WF1G and a WF16G.
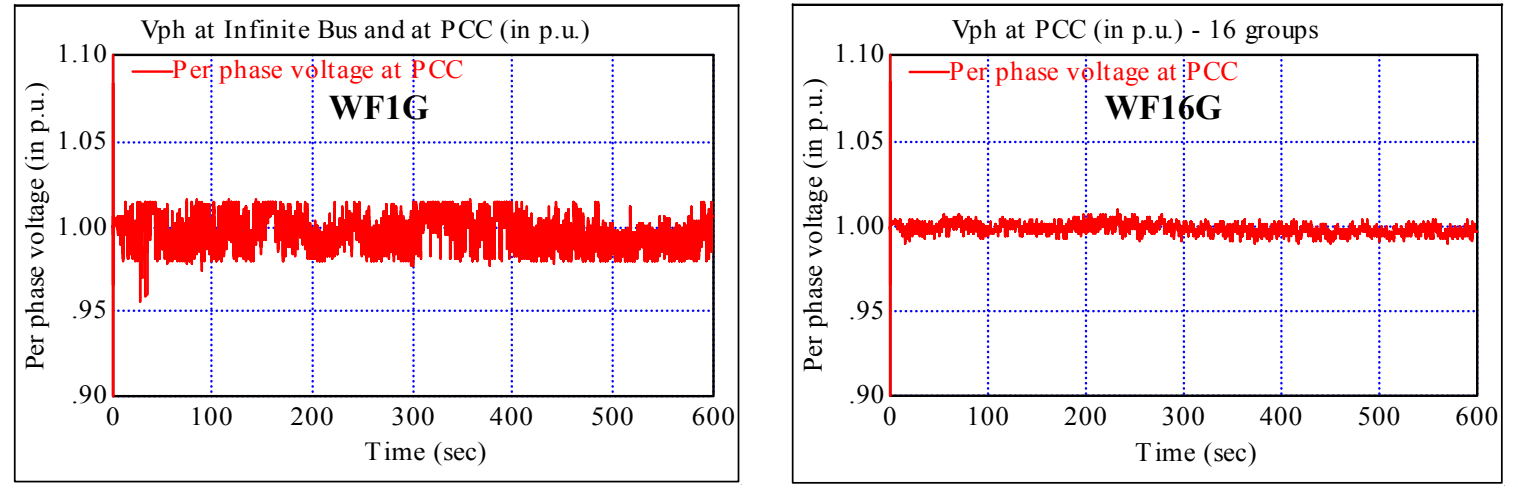

Fig. 5. Comparison of voltage variation at PCC for the wind farm models WF1G and WF116G.

The wind farm output consists of the sum of the output of each individual group. The real power output of the wind farm is shown in Figure 3 between $t=10$ seconds and $t=20$ seconds to capture the fluctuation caused by the tower shadow and the wind turbulence. The output of a WF1G shows a very strong 3P effect; in the WF16G the tower shadow effects seem to cancel out among the groups. The overall power fluctuation, which is the sum of turbulence-induced fluctuation and tower shadow-induced fluctuations, is obviously smoother in the WF16G than in the WF1G.

Figure 4 compares the time series output power variations at the PCC for WF1G and WF16G. The output of the wind farm WF1G is an amplification of the output of one turbine because, in a WF1G, each wind turbine is synchronized. In the trace for the WF16G the amplitude of fluctuations is significantly reduced. The wind turbine aggregation definitely makes the collective power fluctuations at the PCC smoother because of the cancellation effect among wind turbines.

In Figure 5, the voltage variations of WF1G and WF16G are compared. The voltage fluctuations apparently correspond to the real and reactive power fluctuations. The voltage fluctuation for WF1G is much larger than that for WF16G. Although the voltage fluctuations are large in the WF1G system, the voltage variation never reaches $\pm 5 \%$, a generally acceptable limit in the utility industry.

\section{REAL POWER, REACTIVE POWER, AND VOLTAGE AT PCC}

Figure 6 demonstrates that the nature of the output power pulsation in a stall-controlled, fixed-speed wind turbine generator is influenced by three main factors:

- The nature of wind speed variation (average wind speed variation, which is slow, and the turbulence of the wind, which is relatively faster than the change of average wind speed).

- The characteristic of the power curve. (Operation below rated wind speed gives a positive, large slope $\Delta \mathrm{P} / \Delta \mathrm{v}>0$. Operation around rated wind speed $\Delta \mathrm{P} / \Delta \mathrm{v}$ $\simeq 0$ and higher gives a negative, small slope $\Delta \mathrm{P} / \Delta \mathrm{v}<$ 0 .)

- The 3P power pulsation is due to the tower shadow effect. 


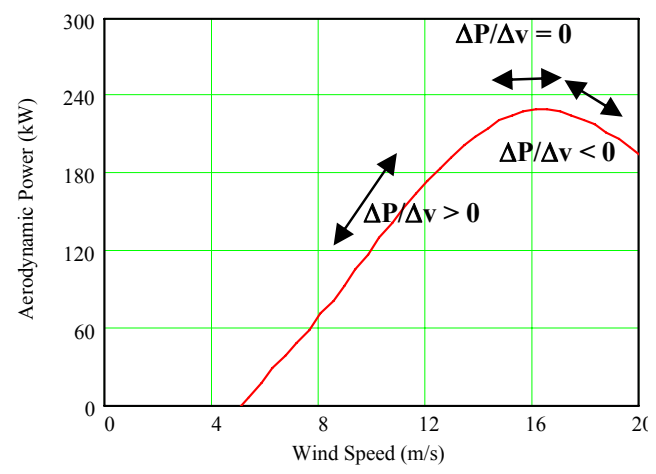

Fig.6. A typical power curve of a wind turbine generator

3P - REAL AND REACTIVE POWER

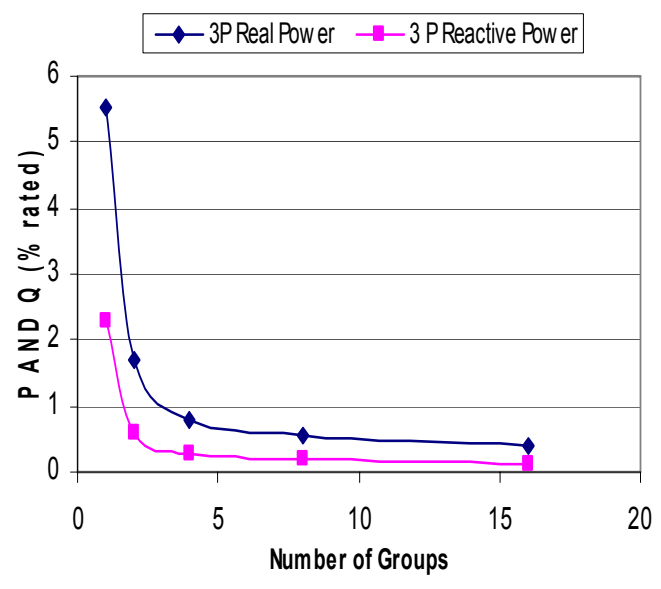

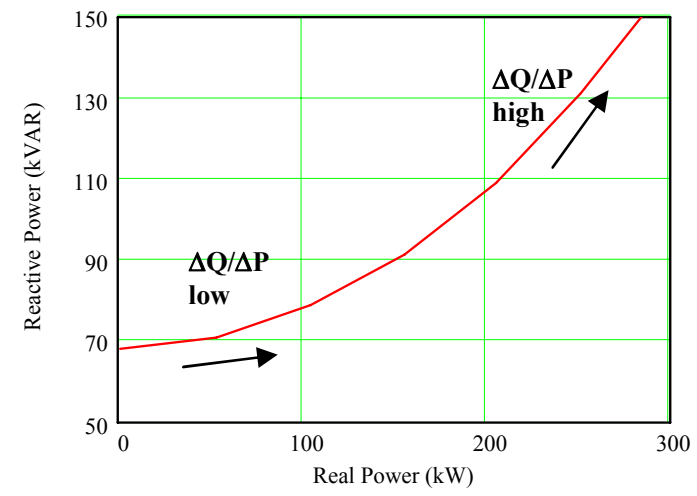

Fig.7. Reactive power demand of a typical induction generator

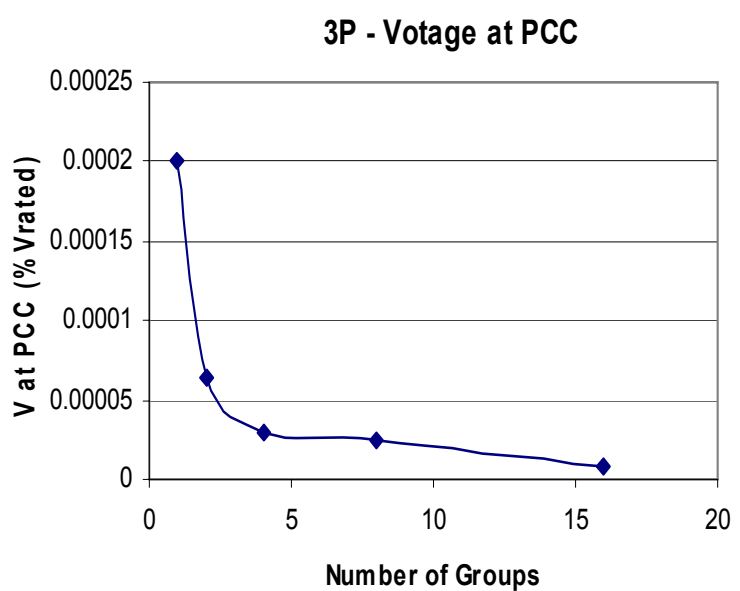

Fig. 8. The 3P components of a wind farm output: (a) Real and reactive power output,

(b) Voltage at the PCC.

In addition, as shown in Figure 7, the variation of real power $(\mathrm{P})$ is accompanied by the variation of reactive power $(\mathrm{Q})$ demand. In an induction generator, reactive power demand increases nonlinearly with real power. The slope $\Delta \mathrm{Q} / \Delta \mathrm{P}$ in a low power region is low; in a high power region it is high.

For both WF1G and WF16G wind farm configurations, the maximum values for both turbines, with and without tower shadow, are almost the same because in the maximum swing, the wind turbine is operated in stall mode (a high wind speed region where an almost flat line can be found on a power curve). The minimum values can be found when the wind turbine operates in the lower wind speed region (linear portion of the power curve). We can expect that the minimum values will be lower for WF1G than for WF16G because of the synchronization of the entire wind farm in the former and of the aggregation effect in the latter.

The variation of the reactive power is affected by the wind speed variation and the tower shadow as in the case of the real power output. We know from the real/reactive power relationship shown earlier, that the reactive power varies nonlinearly with respect to the real power. The P-Q characteristic of an induction machine is probably close to a quadratic relationship as the output real power increases, especially in the higher power region. The maximum values of the reactive power have a wider spread than those of the real power because of the P-Q characteristic of induction machines. The minimum value of the reactive power for WF1G is too small to show, indicating the reactive power swing reaches down to zero. The standard deviation and overall characteristic of the reactive power show a general trend in which the WF1G has a greater variation than the WF16G.

The voltage variation at the $\mathrm{PCC}$ is a result of real and reactive power output variations of the wind farm. The variation of reactive power is more dominant in causing the voltage fluctuation at the PCC, as will be shown later. 
As mentioned in the previous section, each wind turbine is compensated by ac capacitors to improve the reactive power. Although the ac capacitor generates an almost constant reactive power, the variable wind speed causes a variable reactive power to be absorbed by the induction generator.

Our simulations show that the maximum deviation of the PCC voltage above average value occurs when the reactive power absorbed by the wind farm decreases to low values (corresponding to low generation). Thus, this maximum voltage deviation can be correlated to the deviation of reactive and real power below average value. The minimum of the voltage value at PCC occurs (mostly) when the reactive power absorbed by the wind farm increases to high values. Thus this minimum voltage can be correlated to the deviation of the reactive power above average value. The standard deviation and overall characteristic of the voltage at the PCC show a general trend in which the voltage fluctuation for WF1G has a larger voltage variation than that for WF16G.

To appreciate the impact of tower shadow, the amplitudes of the 3Ps component found on the real power, reactive power, and voltage at the $\mathrm{PCC}$ are plotted as a function of the number of groups in a wind farm and shown in Figure 8. The 3P component of the real and reactive power outputs of the wind farm is reduced dramatically as the number of the groups in a wind farm increases. The change of the $3 \mathrm{P}$ components on the real power, reactive power, and voltage at the PCC is significant as the number of group increases. For example, from the WF1G (one group) to the WF2G (two groups), the $3 \mathrm{P}$ drops by about $70 \%$. As the number of groups increases, the $3 \mathrm{P}$ components decrease and practically disappear at WF16G.

The flicker level at the PCC can be computed based on the voltage waveform at the PCC. The voltage at the PCC is computed by feeding the voltage time series into the flicker meter described in the IEC 61000-4-15. The flicker level measures the annoyance level a human eye perceives when a specific light is powered by fluctuating voltage source. Although a high flicker level may not affect sensitive equipment, it may affect the lighting system and cause a flicker that affects eye perception. This annoys human sight and eventually creates fatigue that may lead to a serious accident on the factory floor.

In this paper, the flicker level is measured by applying a time series of voltage at the PCC to the flicker meter. The wind farm groupings were subjected to this measurement and the wind turbines were subjected to a specific average wind speed and turbulence intensity. Since the voltage is affected by the voltage fluctuation, the flicker level at the PCC depends on the fluctuating voltage caused by the tower shadow and the wind turbulence. As the number groupings of the wind turbine increases, the flicker level Pst decreases dramatically (see Figure 9). Although the flicker level is affected by the number of groups in the wind farm and the level of turbulence, it is not directly proportional to the 3Ps. For example, Figure 8 shows that the $3 \mathrm{P}$ component of the voltage at the PCC is dramatically reduced as the number of groups in the wind farms increases from one to two by a factor of about $700 \%$; the Pst level decreases by only a factor of about $25 \%$. As the number of groups in a wind farm increases, the Pst level will finally reach very small values.

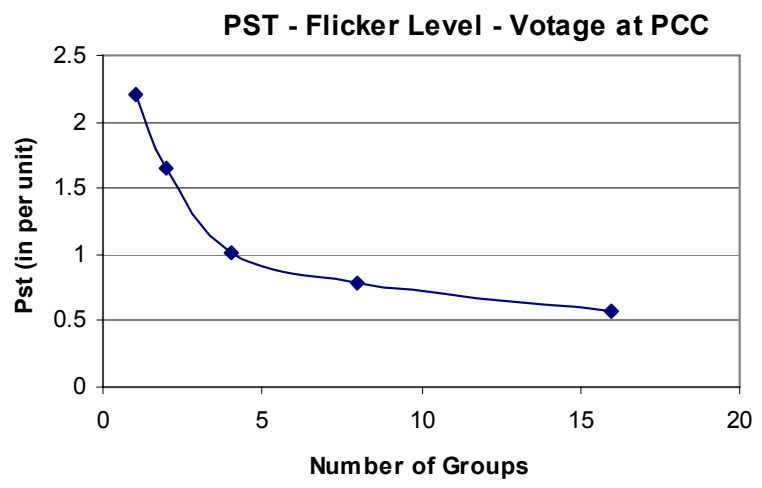

Fig. 9. Pst level of the voltage at the PCC as a function of the number of the groups in the wind farm.

\section{CONCLUSIONS}

This paper investigates the effects of wind turbine aggregation on a large wind farm. The method of analysis used to measure the characteristics of a wind farm plays an important role in determining the final conclusion. Therefore, a wind farm must be represented fairly so it reflects a real wind farm as closely as possible.

- From the power fluctuation perspective, the larger the area of the wind farm the more diverse the wind profile that drives each turbine. Thus, there is a greater chance that the fluctuation in one turbine will be out of phase with another on the other side of the wind farm.

- This paper shows that the more groups used to represent a wind farm, the smaller the fluctuation. The same conclusion can be drawn that a wind farm with more small turbines creates fewer power/voltage fluctuations on the power grid than a few large turbines.

- As the number of turbines in a wind farm increases over a large area, the characteristics of the wind farm are masked by the collective impact. Thus the impact of tower shadow and wind turbulence on the wind farm will be leveled out.

- The Pst level does not decrease in the same fashion as the $3 \mathrm{P}$ components as the number of groups in the wind farm increases. Thus, it shows that the $3 \mathrm{P}$ component is not the main source of flicker. In the real farm, the Pst level is expected to be lower than that represented by the WF16G.

- The collective behavior of the wind farm follows the same pattern of a wind turbine $(\Delta \mathrm{Q} / \Delta \mathrm{P}$ is large at high 
power) and wind turbine characteristics $\left(\Delta \mathrm{P} / \Delta \mathrm{v}_{\text {wind }}\right.$ is low in the high power region).

\section{REFERENCES}

[1] J.W. Smith and D.L. Brooks, "Voltage Impacts of Distributed Wind Generation on Rural Distribution Feeders," in Proceedings of the IEEE Power Engineering Society Transmission and Distribution Conference, v.1, 2001 Transmission and Distribution Conference and Exposition IEEE/PES, 2001, October 28-November 2, 2001, Atlanta, GA, pp. 492-497.

[2] T. Thiringer, T. Petru and C. Liljegren, "Power Quality Impact of a Sea Located Hybrid Wind Park," IEEE Transactions on Energy Conversion, vol. 16, no. 2, June 2001, pp. 123-127.

[3] E. Muljadi, Y. Wan, C. Butterfield and B. Parsons, "A Study of a Wind Farm Power System," A Collection of the 2002 ASME Wind Energy Symposium Technical Papers Presented at the 39th AIAA Aerospace Sciences Meeting and Exhibit, January 14-17, 2002, Reno, NV, pp. 361-370.

[4] A.D. Hansen, P. Sorensen, L. Janosi and J. Bech, "Wind Farm Modeling for Power Quality," IEEE Industrial Electronics Society Conference, November 29-December 2, 2001, Denver, Colorado, pp. 1959-1964.
[5] J. Courault, "Energy Collection on Offshore Wind Farm DC Applications," Second International Workshop on Transmission Networks for Offshore Wind Farms, March 30-31, 2001, Royal Institute of Technology, Electric Power Systems, Stockholm, Sweden.

[6] G. Ronsten, S. Thor H. Ganander, H. Johansson, T. Thiringer, T. Petru and H. Bergstrom, "Evaluation of Loads, Power Quality, Grid Interaction, Meteorological Conditions and Power Performance of the First Swedish Offshore Wind Farm at Bockstigen," Second International Workshop on Transmission Networks for Offshore Wind Farms, March 30-31, 2001, Royal Institute of Technology, Electric Power Systems, Stockholm, Sweden.

[7] M.P. Papadopoulos, S.A. Papthanassiou, N.G. Boulaxis and S.T. Tentzerakis, "Voltage Quality Change by Grid-connected Wind Turbines," European Wind Energy Conference, March 1-5, 1999, Nice, France, pp. 782-785.

[8] H. Amaris, J.Usaola and C. Vilar, "A More Realistic Flicker Coefficient for Wind Turbines Evaluation," European Wind Energy Conference, March 1-5, 1999, Nice, France, pp. 762-765.

[9] Electromagnetic Compatibility (EMC) Part 4: Testing and Measurement Techniques - Section 15: Flicker Meter-Functional and Design Specifications, International Standard IEC 61000-4-15 First edition 1997-11. 


\section{REPORT DOCUMENTATION PAGE}

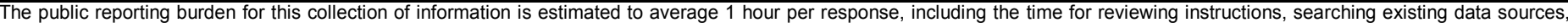

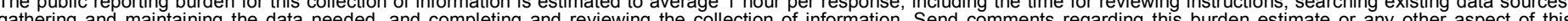

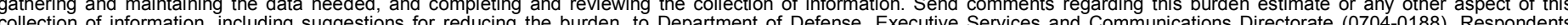

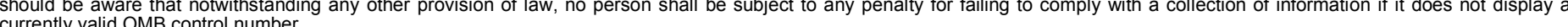

PLEASE DO NOT RETURN YOUR FORM TO THE ABOVE ORGANIZATION.

1. REPORT DATE (DD-MM-YYYY) 2. REPORT TYPE $3 . \quad$ DATES COVERED (FrOm - TO)

November 2006

Conference paper

4. TITLE AND SUBTITLE

The Wind Farm Aggregation Impact on Power Quality: Preprint 5a. CONTRACT NUMBER

DE-AC36-99-G010337

5b. GRANT NUMBER

5c. PROGRAM ELEMENT NUMBER

5d. PROJECT NUMBER

NREL/CP-500-39870

5e. TASK NUMBER

WER6.7502

5f. WORK UNIT NUMBER
7. PERFORMING ORGANIZATION NAME(S) AND ADDRESS(ES)

National Renewable Energy Laboratory

1617 Cole Blvd.

Golden, CO 80401-3393
8. PERFORMING ORGANIZATION REPORT NUMBER

NREL/CP-500-39870

9. SPONSORING/MONITORING AGENCY NAME(S) AND ADDRESS(ES)

10. SPONSOR/MONITOR'S ACRONYM(S) NREL

11. SPONSORING/MONITORING AGENCY REPORT NUMBER

12. DISTRIBUTION AVAILABILITY STATEMENT

National Technical Information Service

U.S. Department of Commerce

5285 Port Royal Road

Springfield, VA 22161

13. SUPPLEMENTARY NOTES

14. ABSTRACT (Maximum 200 Words)

This paper explores the effects of wind farm power fluctuations on the power network. A dynamic simulation of a wind farm is performed and the spatial distribution of the wind turbines is considered.

15. SUBJECT TERMS

wind power; wind farm; utility grid integration

\begin{tabular}{l} 
16. SECURITY CLASSIFICATION OF: \\
\begin{tabular}{|l|l|l|}
\hline $\begin{array}{l}\text { a. REPORT } \\
\text { Unclassified }\end{array}$ & b. ABSTRACT & c. THIS PAGE \\
& Unclassified & Unclassified \\
\end{tabular} \\
\hline
\end{tabular}

\begin{tabular}{l|l|} 
17. LIMITATION & 18. \\
OF ABSTRACT & OF PAGES \\
UL &
\end{tabular}

19a. NAME OF RESPONSIBLE PERSON

19b. TELEPHONE NUMBER (Include area code) 